\title{
Chromogranin A assessment in patients with neuroendocrine neoplasm of the small bowel and carcinoid syndrome treated with somatostatin analogues
}

\author{
Paweł Gut ${ }^{1, A-D}$, Agata Czarnywojtek ${ }^{2, C, E, F}$, Marek Ruchała ${ }^{1, E, F}$ \\ ${ }^{1}$ Department of Endocrinology, Metabolism and Internal Medicine, Poznan University of Medical Sciences, Poland \\ 2 Department of Pharmacology, Poznan University of Medical Sciences, Poland \\ A - research concept and design; $\mathrm{B}$ - collection and/or assembly of data; $\mathrm{C}$ - data analysis and interpretation; \\ $\mathrm{D}$ - writing the article; $\mathrm{E}$ - critical revision of the article; $\mathrm{F}$ - final approval of the article
}

\section{Address for correspondence}

Paweł Gut

E-mail: gutpj@poczta.onet.pl

Funding sources

None declared

Conflict of interest

None declared

Received on January 25, 2020

Reviewed on June 2, 2020

Accepted on August 11, 2020

\section{Cite as}

Gut P, Czarnywojtek A, Ruchała M. Chromogranin A assessment in patients with neuroendocrine neoplasm of the small bowel and carcinoid syndrome treated with somatostatin analogues. Adv Clin Exp Med. 2020;29(11):1319-1324. doi:10.17219/acem/126290

DOI

10.17219/acem/126290

Copyright

Copyright by Author(s)

This is an article distributed under the terms of the

Creative Commons Attribution 3.0 Unported (CC BY 3.0)

(https://creativecommons.org/licenses/by/3.0/)

\begin{abstract}
Background. Chromogranin A ( $\mathrm{CgA})$ is one of the non-specific markers measured in the biochemical diagnostics of neuroendocrine neoplasms (NENs).

Objectives. To analyze the CgA levels of patients with carcinoid syndrome who are being treated with somatostatin analogues (SSAs), depending on the histologic maturity of the neoplasm, the degree of liver involvement and the stage of the disease.
\end{abstract}

Material and methods. The study group comprised of 41 patients, including 29 women (70.7\%) and 12 men (29.3\%). All of the patients had undergone surgical removal of the primary site. Hepatic metastases were found in all patients and they all were treated with SSAs. Chromogranin A concentration was determined using the enzyme-linked immunosorbent assay (ELISA)

Results. Among the patients with grade 1 tumors, the mean CgA value was $298.83 \mathrm{ng} / \mathrm{mL}$, whereas in the group with grade 2 tumors, the CgA value was $1498.44 \mathrm{ng} / \mathrm{mL}$, which was a statistically significant difference $(p<0.001)$. In the group of patients with $10 \%$ liver involvement, the mean CgA value was $394.44 \mathrm{ng} / \mathrm{mL}$, whereas in the group of patients with $25 \%$ liver involvement, this value was $1770.63 \mathrm{ng} / \mathrm{mL}$, demonstrating significantly higher values $(p<0.001)$. Among the patients with a progressing disease, the mean $\mathrm{CgA}$ concentration value was $1620.78 \mathrm{ng} / \mathrm{mL}$, whereas in the group of patients with a stable disease, these were considerably lower, amounting to $230.36 \mathrm{ng} / \mathrm{mL}(p<0.001)$.

Conclusions. Assessing CgA level in patients with carcinoid syndrome is helpful in the diagnostics and monitoring of treatment because C $g$ A values depend on the tumor grade and the severity of the disease.

Key words: chromogranin A, carcinoid syndrome, somatostatin analogues 


\section{Introduction}

Neuroendocrine neoplasms (NENs) are characterized by hormonal activity, which is used in diagnosis and monitoring of the treatment. Biochemical markers measured in the blood serum may be specific or non-specific. Nonspecific markers include chromogranin A (CgA) and neuron-specific enolase (NSE). ${ }^{1}$ Chromogranin $\mathrm{A}$ is a highly stable molecule and no special precautions are needed to store the serum or plasma. ${ }^{2-4}$ The highest CgA concentrations have been found in patients with carcinoid syndrome; thus, it is an important marker used in the monitoring and treatment of neuroendocrine cancers and an independent prognostic indicator of survival in patients with NENs. Based on research conducted on patients with carcinoid tumors, it has been determined that $\mathrm{CgA}$ concentration may reflect the severity of the disease and correlate with disease progression. Chromogranin A concentrations are considerably higher in the majority of NEN cases, but particularly high values are observed in the classic carcinoid tumor. ${ }^{5}$ Chromogranin A may also be used as a marker in the estimation of a tumor's rate of growth. The time of CgA concentration doubling is of significant prognostic value, that is, the shorter the doubling time the worse the prognosis. ${ }^{6,7}$ Treatment with somatostatin analogues (SSAs) considerably reduces $\mathrm{CgA}$ concentrations, particularly with carcinoid tumors, by inhibiting the synthesis and release of CgA from tumor cells. In the case of disease progression during treatment with SSAs, elevated CgA concentration may reflect a lack of control over the tumor secretion activity or its growth. ${ }^{8-15}$ The aim of our study was to assess the concentration of CgA in patients with carcinoid syndrome who were continuously treated with SSAs. The study compared patients according to the degree of histological maturity and the degree of liver involvement by metastases, and depending on whether the disease was stable or progressing. The study had a purely clinical aspect - to assess the prognosis of treatment in patients with varying degrees of disease progression.

\section{Material and methods}

The study group comprised 41 patients - 29 women (70.7\%) and 12 men (29.3\%) - diagnosed with a NEN of the small bowel. The mean age of the men was $60.41 \pm 4.90$ years, and for the women it was $64.20 \pm 10.39$ years. All patients had undergone surgical removal of the primary site with histopathological assessment according to the World Health Organization (WHO) 2017 classification. Grade G1 was found in 19 tissue preparations (46.3\%) and the remaining 22 preparations were classified as G2 (53.7\%). All patients underwent detailed imaging diagnostics (abdominal cavity ultrasonography and computed tomography (CT) of the chest, abdominal cavity, and small pelvis) and supplementary biochemical monitoring (CgA, serotonin and 5-HIAA) in order to assess their clinical progress. In each case, cardiologic consultation was performed with echocardiography in order to identify any carcinoid heart disease (tricuspid and pulmonary valve lesions were found in 32 cases). All of the patients were found to have hepatic metastases (10\% liver involvement in 23 cases and $25 \%$ liver involvement in 18 cases). All patients exhibited symptoms of carcinoid syndrome in the form of diarrhea, facial flush, telangiectasia, and myopathic symptoms.

In each case, to qualify the patients for SSA therapy, receptor scintigraphy was performed using ${ }^{99 \mathrm{~m} T c-E D D A} /$ HYNIC-TOC. The degree of radiotracer uptake in liver metastases was assessed according to the qualitative scale developed by E. Krenning (degrees $0-4$ ). In the study group, the radiotracer uptake in the liver ranged between grades 3 and 4 on Krenning's scale. In patients with histological maturity (G1), the radiotracer uptake was grade 4, while in the G2 patients, it was grade 3. It is also worth adding that the degree of radiotracer uptake in patients with disease progression in most cases was grade 3 . The study group was treated with SSAs from 2014 to 2018 and were administered octreotide LAR at a dose of $30 \mathrm{mg}$ (intramuscularly) or lanreotide autogel at a dose of $120 \mathrm{mg}$ (subcutaneously) every 4 weeks. The CgA levels were measured every 3 months. However, the abdominal CT imaging tests every 6 months in order to obtain an objective assessment of the response to treatment according to RECIST $1.1 \mathrm{cri}$ teria. Chromogranin A concentration was determined using enzyme-linked immunosorbent assay (ELISA), using the Cisbio-Bioassays sets (Perkin Elmer, Waltham, USA). The cut-off point for CgA was $100 \mathrm{ng} / \mathrm{mL}$ at an analytical sensitivity of $19 \mathrm{ng} / \mathrm{mL}$, in line with the manufacturer's recommendations.

\section{Statistical assessment}

An analysis of the quantitative variables was performed by calculating the means, standard deviation (SD), medians, minimum quartiles, and maximum values. The MannWhitney test was used to compare the quantitative variables in the 2 groups. Correlation between 2 quantitative variables was analyzed using Pearson's and Spearman's coefficients. A significance level of 0.05 was adopted in the analysis. Thus, all values below 0.05 were interpreted as indicating statistically significant relationships. The analysis was performed in the software R v. 3.3.1 (www.r-project.org).

\section{Results}

\section{Assessment of $\mathrm{CgA}$ concentration depending on histologic maturity}

In the group of patients with G1 tumors $(\mathrm{n}=19)$, the mean $\mathrm{CgA}$ value was $298.83 \pm 99.81 \mathrm{ng} / \mathrm{mL}$, whereas in the $\mathrm{G} 2$ group $(\mathrm{n}=22$ ) the CgA value was $1498.44 \pm 459.64 \mathrm{ng} / \mathrm{mL}$; this represents a significant difference between the groups 
$(\mathrm{p}<0.001 ;$ Table 1). A similar relationship was observed in the analysis of the final CgA concentration values, that is, in the G1 group the mean of the final CgA values was $755.14 \pm 218.33 \mathrm{ng} / \mathrm{mL}$, while in the G2 group it was $3486.88 \pm 1241.35 \mathrm{ng} / \mathrm{mL}$ ( $\mathrm{p}<0.001$; Table 2). The CgA doubling time in the $\mathrm{G} 1$ group was $39.00 \pm 11.13$ months, whereas in the G2 group it was considerably shorter, amounting to $18.81 \pm 11.64$ months. It is worth emphasizing that in the G1 group, the increase in CgA concentration during SSA treatment was significantly lower and more prolonged in comparison to the patients from the G2 group ( $\mathrm{p}<0.001)$. This resulted in a significant increase in progression-free time.

\section{Assessment of $\mathrm{CgA}$ concentration depending on liver involvement}

Among the patients with 10\% liver involvement ( $\mathrm{n}=23$ ), the mean CgA value was $394.44 \pm 120.51 \mathrm{ng} / \mathrm{mL}$, whereas in the group of patients with $25 \%$ liver involvement ( $\mathrm{n}=18$ ), this value was $1770.63 \pm 404.11 \mathrm{ng} / \mathrm{mL}$, representing a statistically significant difference $(\mathrm{p}<0.001$; Table 3$)$. In the case of the final CgA values in the $1^{\text {st }}$ group, the mean of the final CgA values was $566.86 \pm 285.44 \mathrm{ng} / \mathrm{mL}$, whereas in the $2^{\text {nd }}$ group the values were also higher, with a mean of $4123.44 \pm 1874.77 \mathrm{ng} / \mathrm{mL}$ ( $\mathrm{p}<0.001$; Table 4 ). It should be also noted that among patients with $10 \%$ liver involvement, the CgA doubling time was $37.12 \pm 12.99$ months, while in the group with $25 \%$ liver involvement, it was considerably shorter: $15.16 \pm 7.52$ months. In the group of patients with $10 \%$ liver involvement, the increase in CgA value during SSA treatment was statistically lower than in the group of patients with $25 \%$ liver involvement $(\mathrm{p}<0.001)$. This had a considerable impact on extending the progressionfree time.

\section{Assessment of $\mathrm{CgA}$ concentration depending the stage of the disease}

Among the patients for whom the disease was found to be progressing during the SSA treatment $(\mathrm{n}=21)$, the mean CgA concentration was $1620.78 \pm 385.55 \mathrm{ng} / \mathrm{mL}$, whereas in the group of patients with stable disease $(n=20)$, they were considerably lower, amounting to $230.36 \pm 106.44 \mathrm{ng} / \mathrm{mL}$ ( $\mathrm{p}<0.001$; Table 5). The analysis of the final CgA values revealed similar results: the group with a stable disease

Table 1. Mean chromogranin A $(\mathrm{CgA})$ value $[\mathrm{ng} / \mathrm{mL}]$ depending on grading

\begin{tabular}{|c|c|c|c|c|c|c|c|c|c|}
\hline \multirow{2}{*}{ Grading } & \multicolumn{8}{|c|}{ Mean CgA value [ng/mL] } & \multirow{2}{*}{$p$-value* } \\
\hline & $\mathrm{n}$ & mean & SD & median & $\min$ & $\max$ & Q1 & Q3 & \\
\hline G1 & 19 & 298.83 & 99.81 & 220.80 & 144.71 & 836.85 & 190.81 & 253.04 & \multirow{2}{*}{$p<0.001$} \\
\hline G2 & 22 & 1498.44 & 459.64 & 1452.07 & 127.86 & 3801.5 & 547.50 & 2243.63 & \\
\hline
\end{tabular}

* Mann-Whitney test; SD - standard deviation.

Table 2. Final chromogranin A (CgA) value $[\mathrm{ng} / \mathrm{mL}]$ depending on grading

\begin{tabular}{|c|c|c|c|c|c|c|c|c|c|}
\hline \multirow{2}{*}{ Grading } & \multicolumn{8}{|c|}{ Final $\mathrm{CgA}$ value [ng/mL] } & \multirow{2}{*}{ p-value* } \\
\hline & $\mathrm{n}$ & mean & SD & median & $\min$ & $\max$ & Q1 & Q3 & \\
\hline G1 & 19 & 755.14 & 218.33 & 321.34 & 200.76 & 2254.74 & 260.56 & 366.67 & \multirow{2}{*}{$p<0.001$} \\
\hline G2 & 22 & 3486.88 & 1241.35 & 2514.14 & 65.43 & 9876.34 & 1230.38 & 5612.95 & \\
\hline
\end{tabular}

* Mann-Whitney test; SD - standard deviation.

Table 3. Mean chromogranin A $(\mathrm{CgA})$ value $[\mathrm{ng} / \mathrm{mL}]$ depending on the degree of liver involvement

\begin{tabular}{|c|c|c|c|c|c|c|c|c|c|}
\hline \multirow{2}{*}{$\begin{array}{l}\text { Liver involvement } \\
\text { degree }\end{array}$} & \multicolumn{8}{|c|}{ Mean $\mathrm{CgA}$ value $[\mathrm{ng} / \mathrm{mL}]$} & \multirow{2}{*}{$p$-value ${ }^{*}$} \\
\hline & $\mathrm{n}$ & mean & SD & median & $\min$ & $\max$ & $\overline{\mathrm{Q} 1}$ & Q3 & \\
\hline $10 \%$ & 23 & 394.44 & 120.51 & 219.52 & 127.86 & 820.77 & 176.79 & 253.04 & \multirow{2}{*}{$p<0.001$} \\
\hline $25 \%$ & 18 & 1770.63 & 404.11 & 1655.67 & 198.23 & 3801.5 & 745.87 & 2684.41 & \\
\hline
\end{tabular}

* Mann-Whitney test; SD - standard deviation.

Table 4. Final chromogranin $\mathrm{A}(\mathrm{CgA})$ value $[\mathrm{ng} / \mathrm{mL}]$ depending on the degree of liver involvement

\begin{tabular}{|c|c|c|c|c|c|c|c|c|c|}
\hline \multirow{2}{*}{$\begin{array}{l}\text { Liver involvement } \\
\text { degree }\end{array}$} & \multicolumn{8}{|c|}{ Final $\mathrm{CgA}$ value $[\mathrm{ng} / \mathrm{mL}]$} & \multirow{2}{*}{ p-value* } \\
\hline & $\mathrm{n}$ & mean & SD & median & $\min$ & $\max$ & $\overline{\text { Q1 }}$ & Q3 & \\
\hline $10 \%$ & 23 & 566.86 & 285.44 & 321.23 & 65.43 & 2793.61 & 240.43 & 366.67 & \multirow{2}{*}{$p<0.001$} \\
\hline $25 \%$ & 18 & 4123.44 & 1874.7 & 3886.72 & 432.67 & 9876.34 & 1788.93 & 5673.98 & \\
\hline
\end{tabular}

* Mann-Whitney test; SD - standard deviation. 
Table 5. Mean chromogranin A (CgA) value $[\mathrm{ng} / \mathrm{mL}]$ vs stage of disease

\begin{tabular}{|c|c|c|c|c|c|c|c|c|c|}
\hline \multirow{2}{*}{ Stage of disease } & \multicolumn{8}{|c|}{ Mean $\mathrm{CgA}$ value $[\mathrm{ng} / \mathrm{mL}]$} & \multirow{2}{*}{$p$-value* } \\
\hline & $\mathrm{n}$ & mean & SD & median & $\min$ & $\max$ & Q1 & Q3 & \\
\hline PD & 21 & 1620.78 & 385.55 & 1465.06 & 198.23 & 3801.5 & 688.82 & 2264.51 & \multirow{2}{*}{$\mathrm{p}<0.001$} \\
\hline StD & 20 & 230.36 & 106.44 & 196.78 & 127.86 & 587.86 & 172.12 & 231.52 & \\
\hline
\end{tabular}

* Mann-Whitney test; PD - progressing disease; StD - stable disease; SD - standard deviation.

Table 6. Final chromogranin A $(\mathrm{CgA})$ value $[\mathrm{ng} / \mathrm{mL}]$ compared to the stage of disease

\begin{tabular}{|c|c|c|c|c|c|c|c|c|c|}
\hline \multirow{2}{*}{ Stage of disease } & \multicolumn{8}{|c|}{ Final CgA value [ng/mL] } & \multirow{2}{*}{$p$-value* } \\
\hline & $\mathrm{n}$ & mean & SD & median & $\min$ & $\max$ & Q1 & Q3 & \\
\hline PD & 21 & 3841.95 & 750.79 & 2793.61 & 432.67 & 9876.34 & 1677.42 & 5673.23 & \multirow{2}{*}{$p<0.001$} \\
\hline SD & 20 & 328.91 & 99.33 & 293.2 & 65.43 & 1010.16 & 236.02 & 321.79 & \\
\hline
\end{tabular}

* Mann-Whitney test; PD - progressing disease; StD - stable disease; SD - standard deviation.

had a mean level of $328.91 \pm 99.33 \mathrm{ng} / \mathrm{mL}$, which was markedly lower than in the group with a progressing disease, where the values were $3841.95 \pm 750.79 \mathrm{ng} / \mathrm{mL}(\mathrm{p}<0.001$; Table 6). Also, among the patients with disease progression, the CgA doubling time was $15.71 \pm 7.28$ months, whereas in the group with a stable disease it was considerably shorter: $41.40 \pm 8.46$ months.

\section{Discussion}

Advances in the diagnostics and treatment of NENs has led to increased interest in these rare tumors. Assessment of secretory activity in NENs constitutes an important element in the monitoring and assessment of treatment. Our study assessed CgA values in patients with carcinoid syndrome being treated with SSAs, according to the degree of neoplasm histological maturity, the stage of the disease and the degree of liver involvement from metastatic lesions. In the group of patients with G1 tumors ( $n=19)$, both the mean and the final CgA values were significantly lower than in the $\mathrm{G} 2$ group $(\mathrm{n}=22)$. According to the analysis, the patients with 25\% liver involvement had significantly higher CgA concentration, for both mean and final values, than the patients with $10 \%$ liver involvement.

Chromogranin A is a major non-specific biochemical marker which can be tested for in the blood as a circulating tumor marker; its level depends on the type of cells and secretory granules. In their meta-analysis, Zatelli et al. presented the levels of CgA in a group of 123 patients diagnosed with a NEN as the major marker in the monitoring of treatment and prognosis. In their conclusions, the authors emphasized that CgA values are proportionate to the size of the primary site and the number of metastases in the liver. The specificity of CgA measurements is estimated to be $90 \%$, while the sensitivity is $68 \%$ relative to the severity of the disease. ${ }^{16}$ Donica et al., who examined the level of CgA in a group of 41 patients with highly differentiated midgut NENs, reported that the highest CgA concentrations were found in patients with carcinoid syndrome and numerous metastatic lesions in the liver. ${ }^{17}$ Rossi et al., in a study on 91 patients with midgut NENs, demonstrated that a marked increase of $\mathrm{CgA}$ precedes by approx. 6 months a disease progression which is detectable with radiography. ${ }^{18}$ These studies prove that monitoring biochemical markers constitutes an independent prognostic index of the possible disease progression. Similar observations have been documented by Cheng et al., where an increase in CgA level among 122 patients with NENs was associated with later progression in imaging tests. ${ }^{19}$

The observations of Ardill et al. are also noteworthy: they reported that neurokinin A is a more sensitive marker for the monitoring of carcinoid syndrome than CgA or 5 -HIAA. ${ }^{20}$ In a group of 523 patients with a NEN of the small bowel, elevated values of neurokinin A were found in as many as $72.6 \%$ of cases.

In the current study, we also performed an analysis of CgA measurements depending on the stage of the disease. Among the patients whose disease was found to be progressing during SSA treatment $(n=21)$, the mean CgA values were statistically significantly higher than in the group with a stable form of the disease. It should also be noted that among patients with disease progression, the CgA doubling time was 15.71 months, whereas in the group with stable disease, it was considerably shorter, amounting to 41.40 months. Similar observations were made by Tang et al., in a study determining the risk factors of disease progression: the doubling time of CgA concentration in patients with midgut NENs is an important prognostic element. ${ }^{21}$ Similar relationships were observed in the assessment of serotonin and 5-HIAA concentrations. ${ }^{22}$ Raoof et al. presented an assessment of CgA concentration in patients with non-secreting pancreatic NENs as the predictive factor for the decision of whether to treat surgically. Patients with lesions measuring less than $2 \mathrm{~cm}$ in the pancreas and with high CgA levels should be treated surgically. ${ }^{23,24}$ Likewise, Rossi et al. reported that levels of $\mathrm{CgA}$ circulating in the blood are important in the assessment of disease recrudescence and progression, but considerably less so in differential diagnosis. ${ }^{25}$ 
It is currently known that the highest $\mathrm{CgA}$ values are found in NENs of the small bowel, large bowel and pancreas. The highest values have been recorded in carcinoid syndrome with numerous liver metastases. In these assays, the test sensitivity was $85.8 \%$ and the specificity $98.5 \% .{ }^{26-28}$ Oberg and Modlin presented completely new NEN biomarkers in the form of circulating gene transcriptors, micro-RNA or the neoplastic cells themselves originating from the tumor. The sensitivity and specificity of these measurements is significantly higher than CgA measurement. ${ }^{29-33}$ Corsello et al. also presented in their study that the CgA 1-76 fragment, known as vasostatin 1 (VS-1), is a more sensitive marker independent of the use of proton pump inhibitors (PPIs). ${ }^{34}$ Somatostatin analogue treatment reduces CgA concentrations considerably, particularly in patients with carcinoid syndrome, by inhibiting the synthesis and release of CgA from tumor cells and not by reducing tumor mass. In the case of progressing disease during SSA treatment, elevated CgA concentration may reflect a lack of control over the tumor secretion activity or growth. ${ }^{35,36}$ Somatostatin analogues demonstrate an antiproliferative action (cytotoxic or cytostatic), which exerts a direct inhibiting influence on angiogenesis and the induction of apoptosis. Most patients had abnormal fasting blood glucose levels when using SSAs. In rare cases, patients developed non-insulin-dependent diabetes. Gallstones and dyspepsia associated with a suppression of pancreatic exocrine function are common.

The results of the CLARINET study, which concerned the use of lanreotide autogel in NENs, confirmed the antiproliferative effect of SSAs. The study involved 204 patients with NENs of grades 1 and 2 (Ki-67 < 10\%), hormonally non-functioning, with the primary site in the pancreas (45\%), midgut (36\%), hindgut (7\%), or unknown $(13 \%)$; there was $>25 \%$ liver involvement in $33 \%$ of the patients. The two-year treatment with $120 \mathrm{mg}$ of lanreotide autogel every 4 weeks demonstrated no disease progression or death in $62 \%$ of the treated patients, compared with $22 \%$ of patients administered a placebo. ${ }^{37}$

Similar results were obtained in the PROMID study, which used octreotide LAR in patients with midgut G1 neoplasm. In the group of patients administered the drug, the median of progression-free survival time (PFS) was 14.3 months, whereas in the placebo group it was 6.2 months. This study found that the use of octreotide LAR at a dosage of $30 \mathrm{mg}$ for 18 months led to a lack of disease progression in $67 \%$ of patients. ${ }^{38}$ Treatment with longacting SSAs is the treatment of choice in the case of carcinoid syndrome symptoms.

\section{Conclusions}

It should be mentioned that despite the fact that $\mathrm{CgA}$ is not a perfect biomarker, it remains an important element in the diagnostics and monitoring of treatment of NEN patients.

\section{ORCID iDs}

Paweł Gut (D) https://orcid.org/0000-0002-1661-175X

Agata Czarnywojtek (1) https://orcid.org/0000-0003-3595-8449

Marek Ruchała (1) https://orcid.org/0000-0002-6296-7220

\section{References}

1. Nehar D, Lombard Bohas C, Olivieri S. Interest of chromogranin A for diagnosis and follow-up of endocrine tumors. Clin Endocrinol (Oxf). 2004;60(5):644-652.

2. Glinicki P, Jeske W. Chromogranin A (CgA): Characteristics of available research methods and conditions that may affect the results obtained [in Polish]. Endokrynol Pol. 2009;60(5):415-419.

3. Glinicki $P$, Jeske W. Chromogranin A (CgA): The influence of various factors in vivo and in vitro and existing disorders on its concentration in blood. Endokrynol Pol. 2010;61(4):384-387.

4. Nobels FR, Kwekkeboom DJ, Coopmans W, et al. Chromogranin A as serum marker for neuroendocrine neoplasia: Comparison with neuron-specific enolase and the alpha subunit of glycoprotein hormones. J Clin Endocrinol Metab. 1997;82(8):2622-2628.

5. Bilek R, Safarik L, Ciprova V, Vlcek P, Lisá L. Chromogranin A, a member of neuroendocrine secretory proteins, as a selective marker for laboratory diagnosis of pheochromocytoma. Physiol Res. 2008;57(Suppl 1): S171-S179.

6. O'Connor DT, Pandian MR, Carlton E, Cervenka JH, Hslao RJ. Rapid radioimmunoassay of circulating chromogranin A: In vitro stability, exploration of the neuroendocrine character of neoplasia, and assessment of the effects of organ failure. Clin Chem. 1989;35(8): 1631-1637

7. Waldum HL, Syversen U. Serum chromogranin A in the control of patients on long-term treatment with inhibitors of acid secretion. Eur J Clin Invest. 2001;31(9):741-743.

8. Gut P, Czarnywojtek A, Fischbach J, et al. Chromogranin A - unspecific neuroendocrine marker: Clinical utility and potential diagnostic pitfalls. Arch Med Sci. 2016;12(1):1-9.

9. Glinicki P, Kapuścińska R, Jeske W. The differences in chromogranin A concentrations measured in serum and in plasma by IRMA and ELISA methods. Endokrynol Pol. 2010;61(4):346-350.

10. Kos-Kudła B. Treatment of neuroendocrine tumors: New recommendations based on the CLARINET study. Contemp Oncol (Pozn). 2015; 19(5):345-349.

11. Kunikowska J, Królicki L, Sowa-Staszczak A, Pawlak D, Hubalewska-Dydejczyk A, Mikołajczak R. Nephrotoxicity after PRRT: Still a serious clinical problem? Renal toxicity after peptide receptor radionuclide therapy with 90Y-DOTATATE and 90Y/177Lu-DOTATATE. Endokrynol Pol. 2013;64(1):13-20.

12. Kos-Kudła B, Bolanowski M, Handkiewicz-Junak D, Jarząb B. Diagnostic and therapeutic guidelines for gastrointestinal neuroendocrine tumors (recommended by the Polish Network of Neuroendocrine Tumors). Endokrynol Pol. 2008;59(1):41-56.

13. Foltyn W, Zajęcki W, Marek B, et al. The value of the Ki-67 proliferation marker as a prognostic factor in gastroenteropancreatic neuroendocrine tumours. Endokrynol Pol. 2012;63(5):362-366.

14. Fischbach J, Gut P, Matysiak-Grześ $M$, et al. Combined octreotide and peptide receptor radionuclide therapy ((90)Y-DOTA-TATE) in case of malignant insulinoma. Neuro Endocrinol Lett. 2012;33(3): 273-278.

15. Stridsberg M, Eriksson B, Oberg K, Janson ET. A comparison between three commercial kits for chromogranin A measurenents. J Endocrinol. 2003;177(2):337-341

16. Zatelli MC, Torta M, Leon A, et al; Italian CromaNet Working Group. Chromogranin A as a marker of neuroendocrine neoplasia: An Italian Multicenter Study. Endocr Relat Cancer. 2007;14(2):473-482.

17. Donica H, Malecha-Jędraszek A, Strosławska E, Burska A, Szubstarski F. Significance of plasma chromogranin A determination in neuroendocrine tumour (NET) diagnosis. Folia Histochem Cytobiol. 2010; 48(4):603-610.

18. Rossi RE, Garcia-Hernandez J, Meyer T, et al. Chromogranin A as a predictor of radiological disease progression in neuroendocrine tumours. Ann Trans/ Med. 2015;3(9):118.

19. Cheng Y, Sun Z, Bai C, et al. Serum chromogranin A levels for the diagnosis and follow-up of well-differentiated non-functioning neuroendocrine tumors. Tumour Biol. 2016;37(3):2863-2869. 
20. Ardill JE, Armstrong L, Smye M, Doherty R, McCance DR, Johnston BT. Neuroendocrine tumours of the small bowel: Interpretation of raised circulating chromogranin A, urinary 5 hydroxy indole acetic acid and circulating neurokinin A. QJM. 2016;109(2):111-115.

21. Tang C, Gong L, Zou W, et al. Multivariate analysis of metastasis-related risk factors for patients with gastroenteropancreatic neuroendocrine tumors based on clinicopathological and endoscopic features. Oncol Rep. 2016;36(6):3343-3352.

22. Allen KR, Degg TJ, Anthoney DA, Fitzroy-Smith D. Monitoring the treatment of carcinoid disease using blood serotonin and plasma 5-hydroxyindoleacetic acid: Three case examples. Ann Clin Biochem. 2007;44(Pt 3):300-307.

23. Raoof M, Jutric Z, Melstrom LG, et al. Prognostic significance of chromogranin A in small pancreatic neuroendocrine tumors. Surgery. 2018;165(4):760-766.

24. Jun E, Kim SC, Song KB, et al. Diagnostic value of chromogranin A in pancreatic neuroendocrine tumors depends on tumor size: A prospective observational study from a single institute. Surgery. 2017; 162(1):120-130.

25. Rossi RE, Ciafardini C, Sciola V, Conte D, Massironi S. Chromogranin $A$ in the follow-up of gastroenteropancreatic neuroendocrine neoplasms: Is it really game over? A systematic review and meta-analysis. Pancreas. 2018;47(10):1249-1255.

26. Hofland J, Zandee WT, de Herder WW. Role of biomarker tests for diagnosis of neuroendocrine tumours. Nat Rev Endocrinol. 2018; 14(11):656-669.

27. Lyubimova NV, Churikova TK, Kushlinskii NE. Chromogranin as a biochemical marker of neuroendocrine tumors. Bull Exp Biol Med. 2016; 160(5):702-704.

28. Di Giacinto P, Rota F, Rizza L, et al. Chromogranin A: From laboratory to clinical aspects of patients with neuroendocrine tumors. Int J Endocrinol. 2018;2018:8126087.

29. Oberg K, Modlin IM, De Herder W, et al. Consensus on biomarkers for neuroendocrine tumour disease. Lancet Oncol. 2015;16(9):435-446.
30. Modlin IM, Oberg K, Taylor A, Drozdov I, Bodei L, Kidd M. Neuroendocrine tumor biomarkers: Current status and perspectives. Neuroendocrinology. 2014;100(4):265-277.

31. Genç CG, Jilesen APJ, Nieveen van Dijkum EJM, et al. Measurement of circulating transcript levels (NETest) to detect disease recurrence and improve follow-up after curative surgical resection of well-differentiated pancreatic neuroendocrine tumors. J Surg Oncol. 2018; 118(1):37-48.

32. Modlin IM, Kidd M, Malczewska A, et al. The NETest: The clinical utility of multigene blood analysis in the diagnosis and management of neuroendocrine tumors. Endocrinol Metab Clin North Am. 2018; 47(3):485-504

33. Malczewska A, Bodei L, Kidd M, Modlin IM. Blood mRNA measurement (NETest) for neuroendocrine tumor diagnosis of image-negative liver metastatic disease. J Clin Endocrinol Metab. 2019;104(3): 867-872.

34. Corsello A, Di Filippo L, Massironi S, et al. Vasostatin-1: A novel circulating biomarker for ileal and pancreatic neuroendocrine neoplasms. PLoS One. 2018;13(5):e0196858. doi:10.1371/journal.pone.0196858

35. Kruljac I, Vurnek I, Maasberg S, et al. A score derived from routine biochemical parameters increases the diagnostic accuracy of chromogranin A in detecting patients with neuroendocrine neoplasms. Endocrine. 2018;60(3):395-406. doi:10.1007/s12020-018-1592-6

36. Tseng CM, Cheng TY, Chen TB, et al. Low accuracy of chromogranin A for diagnosing early-stage pancreatic neuroendocrine tumors. Oncol Lett. 2018;15(6):8951-8958. doi:10.3892/ol.2018.8472

37. Caplin ME, Pavel M, Ćwikła JB, et al. Anti-tumour effects of lanreotide for pancreatic and intestinal neuroendocrine tumours: The CLARINET open-label extension study. Endocr Relat Cancer. 2016;23(3):191-199.

38. Arnold R, Müller H, Schade-Brittinger C, et al; PROMID Study Group. Placebo-controlled, double-blind, prospective, randomized study of the effect of octreotide LAR in the control of tumor growth in patients with metastatic neuroendocrine midgut tumors: A report from the PROMID study group. J Clin Oncol. 2009; 27(28):4656-4663. 